\title{
Эффективность трансформации компаний открытого типа в компании закрытого типа на развитых рынках капитала: обзор исследований
}

\author{
Романов К.И. ${ }^{29}$
}

В настоящей статье рассматриваются теории, подтверждающие эффективность трансформаџии компаний открытого типа в компании закрытого типа, разработанные на развитых рынках капитала в конще XX столетия, а также эмпирические исследования, подтверждающие достоверность этих теорий. Как теории, так и эмпирические исследования строятся на данных о сделках LBO (Leveraged buyout), которые были популярны на развитых рынках капитала в 80-е годы ХХ века.

\section{JEL: $G 34 ; G 14$}

Ключевые слова: частные компании, публичные компании, трансформация компаний, предпринимательская теория, теория агентских издержек

\section{1. Введение}

Проблема эффективности трансформации компаний открытого типа в компании закрытого типа возникла в финансовой литературе в 80-е годы XX века, когда огромную популярность приобрели сделки LBO (Leveraged buyout), означающие выкуп акций компании с привлечением больших объемов долгового финансирования. При этом сделка структурируется таким образом, что долги берутся на компанию. Сторонники таких сделок считают, что благодаря высокому уровню долга удается повысить эффективность функционирования компаний. Этот позитивный эффект достигается за счет того, что высокий уровень долга стимулирует менеджмент работать более эффективно: менеджеры, будучи единственными акционерами компании, начинают работать более эффективно, ведь компания может существенно экономить на налоговых платежах и т.д. Противники LBO считают, что менеджмент компании после таких сделок выводит все потоки и ценные активы, хорошо зарабатывая на этой операции и разрушая при этом эффективно действовавшую компанию.

В данном исследовании мы рассмотрим теории, объясняющие эффективность LBO на развитых рынках капитала, а также эмпирические исследования, доказывающие этот тезис. Сначала мы рассматриваем описание существующих теорий, объясняющих эффективность LBO (раздел 2). Затем мы подробнее остановимся на поведенческих аспектах, которые приводят к росту эффективности компании после LBO. Поведенческие теории объясняют рост эффективности компании с позиций появления у менеджмента компании предпринимательского взгляда на бизнес. Также мы сравним объяснение причин эффективности LBO согласно поведенческой теории с объяснениями теории агентских издержек (раздел 3). В разделе 4 будет проведена эмпирическая проверка теории предпринимательства (поведенческой теории). В разделе 5 приводится эмпирическая проверка теории агентских издержек.

В разделе 6 проводится анализ эффективности сделок LBO на основе группы показателей, после чего каждый из показателей анализируется с позиций пяти основных теорий. В разделе 7 приводятся выводы.

\footnotetext{
${ }^{29}$ Аспирант кафедры экономики и финансов фирмы ГУ ВШЭ.

Выпуск \#2(6), 2008 구의 Элекронный журнал Корпоративные Финансы, 2008
} 


\section{2. Основные теоии, объясняющие эффективность сделок LBO}

Существует несколько теоретических концепций возможного роста эффективности деятельности компании в результате LBO [Bull, 1989]:

1. Возникновение «предпринимательского» взгляда на бизнес. Новая группа владельцев бизнеса достаточно малочисленна и часто включает топ-менеджеров компании. Таким образом, владельцы оказываются непосредственно вовлечены в бизнес, изменяются стимулы, интересы, система компенсации менеджеров, что положительно влияет на деятельность управляемой ими компании.

2. Теория агентских издержек также предсказывает положительное влияние LBO, но с другой точки зрения. Согласно данной концепции, выкуп акций приводит к снижению агентских издержек вследствие уменьшения конфликта интересов собственников и менеджмента [Jensen, Meckling, 1976].

3. Теория свободного денежного потока. Некоторые исследователи считают, что основной причиной поглощения компании являются высокие агентские издержки вследствие конфликта интересов менеджеров и собственников по поводу распоряжения свободным денежным потоком компании [Jensen, 1986]. Максимизация стоимости бизнеса для акционеров предполагает, что весь свободный денежный поток выплачивается собственникам компании, однако менеджеры предпочитают удерживать часть потока: например, они могут инвестировать средства в активы с доходностью ниже стоимости капитала. Возросший уровень долгового финансирования в результате LBO снижает размер свободного денежного потока, доступного менеджерам, тем самым уменьшая конфликт интересов и способствуя росту эффективности бизнеса.

4. Снижение «политических» издержек. Когда компания переходит из открытого типа в компанию закрытого типа, снижаются издержки на обслуживание акционеров, раскрытие информации, соответствие законодательным требованиям, поддержание отношений с аналитиками и т.д. Владельцы компании после LBO могут сосредоточиться на достижении своих собственных целей и не беспокоиться о внимании общественности.

5. Снижение налогового бремени. Рост уровня заемного капитала в результате LBO предполагает возможность уменьшения налоговой базы за счет выплаты процентов по долгу. Однако многие экономисты не считают это преимущество реальной выгодой с точки зрения общества, поскольку в данном случае уменьшение подоходных налогов является лишь перераспределением налогового бремени между другими плательщиками.

\section{3. Поведенческие теории}

Современные теории, основанные на поведенческих финансах, бурно развивавшиеся в конце XX - начале XXI века, позволяют по-новому взглянуть на объяснение причин популярности трансформаций компаний открытого типа в компании закрытого типа, имеющих место в США в 80-е годы XX века в виде LBO.

Взгляд на увеличение потенциала компании благодаря появлению предпринимательских инициатив у менеджмента после превращения компании в частную предлагается в статье Райта, Хоскиссона и Бузеница [Wright, Hoskisson, Busenitz, 2000]. В статье рассматриваются причины эффективности трансформации компаний открытого типа, a также государственных компаний в компании закрытого типа. Благодаря изменению мышления менеджмента на предпринимательское, эффективность управления компанией после ее трансформации в компанию закрытого типа возрастает. Кроме того, стимулы к поведению менеджмента изменяются после того, как менеджеры становятся собственниками компании. 
По мнению авторов статьи, теория агентских издержек и прав собственности, разрабатываемая Демсецом [Demsetz, 1967], Дженсеном и Меклингом [Jensen \& Meckling, 1976] применительно к частным компаниям, а также Эндюсом и Доулингом [Andrews \& Dowling, 1998], Ухленбраком и Декастро [Uhlenbruck \& De Castro, 1998] для государственных компаний не в полной мере описывает причины эффективности трансформации этих компаний в частные компании закрытого типа. Авторы утверждают, что помимо возникающих новых стимулов для более эффективного управления, менеджмент получает большую свободу действий, что дает ему возможность проявить свои предпринимательские способности. Это позволяет быстрее осмысливать сложные нетипичные ситуации с высоким уровнем неопределенности и принимать нестандартные решения. Более широкое использование эвристик ${ }^{30}$ предпринимателями, которыми становятся менеджеры после выкупа акций компаний, позволяет более полно использовать появляющиеся новые возможности. Предприниматели работают в условиях высокой неопределенности и применяют специальные эвристики с целью проанализировать имеющуюся в наличии информацию и принять решение на ее основе. Без использования эвристик процесс принятия решений был бы слишком сложным и дорогостоящим. Сравнение теории предпринимательских способностей и теории агентских издержек приводится в таблице 1.

Таблица 1.

Сравнение теории предпринимательских способностей с теорией агентских издержек

\begin{tabular}{|c|c|c|}
\hline Критерий сравнения & $\begin{array}{l}\text { Теория } \quad \text { предприниматель- } \\
\text { ских способностей }\end{array}$ & Теория агентских издержек \\
\hline $\begin{array}{l}\text { Взгляд на индивидуальное } \\
\text { поведение }\end{array}$ & $\begin{array}{l}\text { Индивидуальное поведение } \\
\text { базируется на эвристиках }\end{array}$ & $\begin{array}{l}\text { Менеджерами } \\
\text { только денежные стимулы }\end{array}$ \\
\hline $\begin{array}{l}\text { Роль владения менеджмен- } \\
\text { том долей в акционерном } \\
\text { капитале компании }\end{array}$ & $\begin{array}{l}\text { Владение } \\
\text { использовать предпринима- } \\
\text { тельские способности }\end{array}$ & \begin{tabular}{lcr} 
Совмещение & владения & и \\
управления & приводит & к \\
совпадению & \multicolumn{2}{c}{ стимулов } \\
менеджеров и акционеров
\end{tabular} \\
\hline Принятие решений & $\begin{array}{l}\text { Быстро изменяющаяся } \\
\text { сложная } \\
\text { анализируется при пос-среда } \\
\text { эвристик, что позволяет } \\
\text { быстро распознать только } \\
\text { появляющиеся тренды }\end{array}$ & $\begin{array}{l}\text { Решения } \\
\text { оринимаются на } \\
\text { количественному } \\
\text { определению информации и } \\
\text { реализации корпоративных } \\
\text { процедур }\end{array}$ \\
\hline Взгляд на риск & $\begin{array}{l}\text { Использование } \\
\text { возможностей } \quad \text { берет } \\
\text { над беспокойством о рисках }\end{array}$ & $\begin{array}{l}\text { Менеджеры не приемлют } \\
\text { риск }\end{array}$ \\
\hline Информация & $\begin{array}{l}\text { Недоступная стратегическая } \\
\text { информация появляется на } \\
\text { основе опыта менеджера и } \\
\text { логики, базирующейся на } \\
\text { эвристиках }\end{array}$ & $\begin{array}{l}\text { Информация } \\
\text { товаром, который } \\
\text { приобрести }\end{array}$ \\
\hline Инновации & $\begin{array}{l}\text { Возможность } \quad \text { введения } \\
\text { радикальных инноваций }\end{array}$ & $\begin{array}{lr}\text { Инновации } & \text { производятся } \\
\text { постепенно } & \text { и } \\
\text { заимствуются у конкуресую } \\
\text { занов }\end{array}$ \\
\hline
\end{tabular}

\footnotetext{
${ }^{30}$ Термин «эвристика» означает набор упрощающих стратегий, которые индивид использует с целью принятия стратегических решений в сложных ситуациях в условиях неопределенности информации.

Выпуск \#2(6), 2008

() Электронный журнал Корпоративные Финансы, 2008
} 
Авторы разделяют все LBO, проводимые менеджментом компаний, на четыре основных типа:

1) выкуп, ориентированный на повышение эффективности компании (EfficiencyOriented Buyouts);

2) выкуп, направленный на возрождение компании (Revitalization Buyouts);

3) предпринимательский выкуп (Entrepreneurial Buyouts);

4) неудачная попытка выкупа (Buyout Failures). Buyouts)

Выкуп, ориентированный на повышение эффективности компании (Efficiency-Oriented

Сторонники теории агентских издержек фокусировались на решении проблем излишней диверсификации, избыточных инвестиций и проблем с учетом издержек, которые возникали вследствие несовпадения стимулов менеджмента с интересами акционеров. Особенно эти проблемы характерны для зрелых отраслей, где компании генерируют стабильно высокие свободные денежные потоки [Jensen, 1989]. Более концентрированная структура собственности, более строгие стандарты управления и более эффективная схема вознаграждения менеджмента способствуют борьбе с неоправданным ростом издержек. После выкупа акций менеджментом стоимость компании создается с помощью появления стимулов, препятствующих направлению больших неэффективных инвестиций в зрелые отрасли. Высокий финансовый рычаг в таких случаях служит ограничителем излишней свободы действий менеджеров компании.

После выкупа акций менеджментом компании у него появляются денежные стимулы к более эффективному управлению компанией [Jensen \& Meckling, 1976]. Эмпирические исследования демонстрируют, что выкупы, ориентированные на повышение эффективности компаний, приводят к улучшению операционных и финансовых показателей и денежных потоков компании [Kaplan, 1989]. Подобный тип выкупа характерен для зрелых отраслей, где недостаток инноваций является менее вероятной причиной низкой конкурентоспособности компании в отрасли.

Выкуп, направленный на возрождение компании (Revitalization Buyouts)

Любой компании необходимо поддерживать определенный уровень инноваций с целью сохранять некоторый уровень конкурентоспособности. При этом инновационная активность сопровождается длинными временными горизонтами, непредсказуемостью, большими трудозатратами и высокими рисками [Holmstrom, 1989]. При этом инновационную деятельность трудно стимулировать формальными методами, так как издержки мониторинга и создания правильных стимулов слишком высоки [Francis \& Smith, 1995]. Эта проблема усугубляется в больших компаниях вследствие отсутствия адекватных показателей эффективности деятельности подразделений компании и высоких издержек получения необходимой информации. В результате бюрократия больших компаний существенно ограничивает инновационную деятельность, поскольку препятствует проведению экспериментов. Увеличение уровня долгового финансирования позволяет сделать акционерный капитал более концентрированным, создавая более эффективные стимулы для принятия в расчет долгосрочных последствий принимаемых решений [Williamson, 1985].

Таким образом, независимость является важнейшим условием для проведения инновационной деятельности. В результате выкуп менеджментом акций компании может эффективно стимулировать инновационную деятельность в ней и сделает работу более эффективной, что найдет отражение в росте финансовых показателей компании. Возрождение инноваций достигается за счет того, что менеджмент, используя эвристики, принимает решения, какие инновации внедрять, создавая тем самым стоимость компании.

Предпринимательский выкуп (Entrepreneurial Buyouts) 
Литература, касающаяся LBO, часто игнорирует этот тип выкупа, поскольку в его основе, как правило, лежит агентская теория. Поведенческая теория гласит, что необходимо принимать во внимание когнитивные возможности менеджмента. Проведение менеджментом компании предпринимательского выкупа имеет своей целью облегчение процедур принятия решений, которое поощряло бы принятие риска путем применения эвристик, что отражалось бы в долгосрочном вознаграждении менеджмента, который после выкупа стал собственником компании.

Исследование около 200 компаний [Robbie, Wright \& Albrighton, 1999], выходивших из инвестиций в высокотехнологичные дивизионы, показывает:

1) выкупаемые компании часто имеют непрофильные виды бизнеса;

2) менеджмент материнской компании не понимает технологию;

3) менеджеры пытаются самостоятельно развивать свою собственную стратегию;

4) менеджеры пытаются заработать дополнительные доходы вне строгой системы вознаграждения, установленной материнской компанией.

Предпринимательские выкупы благодаря увеличению уровня концентрации собственности у менеджмента становятся важнейшим фактором, развивающим и стимулирующим научно-техническую деятельность [Francis \& Smith, 1995]. При этом развивать такую деятельность могут лишь менеджеры, обладающие соответствующими навыками. Менеджеры, не обладающие необходимыми предпринимательскими навыками, не смогут использовать появившиеся после выкупа новые возможности.

Таким образом, поведенческая теория говорит о том, что выкуп компании менеджментом всегда позитивно отражается на ее деятельности. Причины выкупа различаются в зависимости от отрасли и ситуации в компании. Авторы провели соответствующее исследование и разбили все случаи на несколько групп, в рамках которых было проведено более подробное исследование.

\section{4. Проверка теории предпринимательства}

Рассмотрим исследование Захра [Zahra, 1995], выявляющее влияние выкупа акций компании на результаты ее деятельности. В данной статье акцент делается на изменение склонности компании к риску, к использованию инноваций в производстве в результате выкупа акций компании менеджерами.

Среди всех сделок LBO выделяются сделки Management Buyout (MBO) - выкуп компании с привлечением заемного капитала группой управляющих самой компании. Менеджеры финансируют покупку компании, считая, что это даст им большую свободу в принятии решений, позволит повлиять на вложение средств в проекты, направленные на улучшение результатов деятельности бизнеса в долгосрочной перспективе, к примеру на вложения в исследования и разработки.

Склонность менеджеров после LBO к использованию инноваций и рискованным инвестициям - достаточно спорный вопрос. С одной стороны, привлечение заемного финансирования заставляет руководство компании сконцентрироваться на краткосрочных тактических целях - генерации денежного потока и выплате долга. Но с другой стороны, рост уровня долга означает более пристальное внимание кредиторов к руководству компании, что, в свою очередь, заставляет менеджеров приложить усилия к росту стоимости компании в долгосрочном периоде. К тому же долговое бремя вынуждает менеджеров избавляться от нерентабельных и непрофильных бизнесов, что ведет к росту эффективности и снижению убытков. Высокий уровень участия менеджеров в капитале компании означает, что их благосостояние привязано к долгосрочным результатам бизнеса, а это является хорошим стимулом для инвестиций в проекты, направленные на создание стоимости.

Многие экономисты выделяли «предпринимательский взгляд» на управление как одну из особенностей компаний после LBO. Данное исследование ставит своей целью оценить, как именно меняется «предпринимательская» деятельность компании после LBO и 
результаты бизнеса, а также выявить связь предпринимательской активности бизнеса и финансовых результатов бизнеса после LBO. Автор вводит термин «корпоративное предпринимательство» (corporate entrepreneurship - CE) - комбинация усилий компании в области рискованных инвестиций, внедрения инноваций, вложений в научные разработки. Если инвестиции в R\&D после выкупа акций уже исследовались во многих статьях, автор считает, что и прочие элементы CЕ способны значительно повлиять на результаты бизнеса.

Автор выделяет три направления объяснения преимущество выкупа акций: налоговая экономия, оппортунистическое поведение менеджеров и снижение издержек открытой формы организации. Некоторое время мотив выигрыша от снижения налогов считался основным мотивом LBO [Lowenstein, 1985], однако экономия на налоговых платежах может быть перекрыта расходами на проведение сделки, поэтому это не единственное объяснение преимуществ LBO.

Менеджеры могут извлечь выгоду, выкупив акции компании, если знают, что она недооценена рынком. В этом случае премия, полученная акционерами, будет ниже реальной стоимости фирмы. Однако вероятность больших выгод для менеджеров невелика, поскольку могут появиться конкурирующие заявки на покупку компании.

Снижение издержек, связанных с публичной формой компании (ранее приведенных как «политические» издержки), способствует росту стоимости бизнеса. Компания, не обремененная требованиями законодательства, публичного раскрытия информации, может больше ресурсов направить на предпринимательскую деятельность.

Как уже говорилось, когда менеджеры компании становятся ее же владельцами, меняется направленность их интересов в сторону долгосрочного роста стоимости бизнеса, появляется стимул внедрения стратегических изменений, избавления от неприбыльных активов. Опять же, избыточный денежный поток может быть направлен на реализацию предпринимательских усилий компании.

При большом количестве акционеров с незначительной долей акций у каждого возникают проблемы мониторинга и контроля действий менеджеров (так называемая проблема «безбилетника»). После LBO менеджеры отвечают перед небольшой группой владельцев, имеющих возможность хорошо контролировать действия менеджеров, тем самым снижая вероятность оппортунистического поведения.

Помимо всего прочего LBO предполагает изменения в системе корпоративного управления компанией: как правило, в составе совета директоров растет доля владельцев бизнеса и резко сокращается доля «посторонних» - специалистов в разных сферах, известных людей.

Итак, LBO приводит к определенным изменениям в компании: рост доли бизнеса в руках менеджеров дает им больше возможностей принимать стратегические решения. Зависимость благосостояния менеджеров от стоимости компании в долгосрочной перспективе заставляет их сосредоточиться на действиях, способствующих созданию стоимости, избавляться от нерентабельных активов, оптимизировать стратегию компании. Из-за высокого уровня долга менеджеры стремятся не к увеличению прибыли, а к максимизации денежных потоков. Это достигается путем генерирования доходов из существующих бизнесов либо инвестированием в новые сферы деятельности. Внедрение инноваций способствует росту производительности, рискованные инвестиции могут увеличить число центров прибыли организации. В целом эти изменения подстегивают склонность компании к корпоративному предпринимательству.

Автор ставит своей целью проверку гипотез об увеличении склонности компании к предпринимательской деятельности после LBO (H1), об улучшении результатов деятельности компании после $\mathrm{LBO}(\mathrm{H} 2)$, а также о положительной взаимосвязи между корпоративным предпринимательством и улучшением финансовых результатов компании (H3).

Как уже подчеркивалось, проблема исследования компаний после LBO заключается в недостатке информации в общедоступных источниках. В данном исследовании автор 
использует информацию о компаниях после LBO, полученную из интервью менеджеров этих компаний. Исследуемые фирмы соответствуют следующим требованиям: по крайней мере, $25 \%$ компании должно быть приобретено топ-менеджерами; компания прошла через LBO и оставалась закрытой в течение исследуемого периода; LBO имело место за 3 года до проведения данного исследования. Данные, полученные из интервью, проверялись на соответствие информации из открытых источников.

Анализируемая выборка включает 47 компаний, средний размер активов составляет 789,1 млн. долларов, средний возраст компаний - 46,7 года, среднее число работников 6734 человека. Исследовались показатели деятельности за 3 года до и 3 года после LBO, год проведения выкупа не включался в исследование.

Автор рассчитывает несколько групп показателей, охватывающих различные аспекты деятельности компаний:

- Корпоративное предпринимательство - инновации и венчурные инвестиции. Группа показателей, относящихся к инновациям, включает: расходы на $\mathrm{R} \& \mathrm{D}$, склонность компании к R\&D, развитие и внедрение новых продуктов, модификации существующих продуктов, «коммерциализация» (быстрота внедрения изменений и новых продуктов), использование внешних источников $\mathrm{R} \& \mathrm{D}$, квалификация сотрудников в сфере $\mathrm{R} \& \mathrm{D}$, рост штата сотрудников в сфере R\&D.

- Склонность к рискованному инвестированию оценивается следующими показателями: доля новых отраслей (где компания работает менее года) в доходе; число новых бизнесов, куда инвестировала исследуемая компания; и число новых для компании сегментов рынка.

- Результаты деятельности компаний анализируются по таким коэффициентам, как производительность сотрудников - отношение объема продаж к числу постоянных сотрудников компании; отношение объема продаж к активам (Sales/Beginning Assets); рентабельность инвестиций (ROI); и отношение EBIT к активам компании (EBIT/Assets).

Также рассчитывается несколько контрольных переменных, влияющих на взаимосвязь между корпоративным предпринимательством и финансовыми результатами компании:

- Технологические возможности - этот показатель представляет собой экспертную оценку уровня инновационности отрасли, возможностей продуктовых и технологический инноваций; существует взаимосвязь между технологическими возможностями отрасли и уровнем инвестиций в $\mathrm{R} \& \mathrm{D}$, и соответственно этот показатель важен для исследования предпринимательских возможностей организации.

- Размер компании (размер активов); считается, что маленькие компании более активно внедряют инновации, так как могут быстрее реагировать на изменения рынка, а также нуждаются в инновационных продуктах и технологиях, чтобы держаться на рынке. С другой стороны, большие компании обладают большими возможностями исследования и внедрения новых технологий. Поскольку высокий уровень долга ограничивает свободу в распоряжении ресурсами, поддерживаются только наиболее важные исследования.

- Возраст компании; чаще зрелые компании менее инновационны, чем молодые, поскольку старым компаниям присуща достаточно формализованная структура, не способствующая внедрению новых технологий; к тому же зрелые компании больше полагаются на маркетинговые технологии для поддержания положения на рынке, нежели на введение новых продуктов.

- Уровень долга в структуре капитала; существуют противоречивые точки зрения о том, как заемное финансирование влияет на склонность к корпоративному предпринимательству. С одной стороны, большой уровень долга накладывает ограничения на распоряжение денежным потоком компании, негативно влияя на возможность предпринимательских действий. Но с другой стороны, строгий контроль за менеджерами компании заставляет их заботиться о долгосрочном процветании 
компании. Таким образом, зависимость склонности к предпринимательству от уровня долга неочевидна и, скорее всего, в каждом случае определяется конкретными условиями.

Указанные показатели рассчитаны для периодов до и после LBO, рассчитываются усредненные значения за 3 года до выкупа компании и соответственно 3 года после LBO.

Анализ значимости изменения группы показателей, отражающих склонность компании к инновациям и венчурным инвестициям, подтвердил гипотезу (H1) о том, что уровень корпоративного предпринимательства вырос после LBO.

Тестирование гипотез (H2) об изменении результатов деятельности после LBO показало, что улучшение показателей прибыльности и производительности бизнеса значимо. Причем автор проанализировал различие показателей внутри самих компаний, а также сравнил результаты компаний после LBO со средними отраслевыми показателями. Таким образом, данное исследование подтвердило, что прибыльность и производительность компаний после LBO значимо выше по сравнению с периодом до LBO; а также результаты компаний после LBO превышают среднеотраслевые показатели.

Для проверки связи предпринимательской активности и финансовых результатов автор построил несколько множественных регрессий, где в роли зависимой переменной выступали показатели прибыльности и производительности компаний после $\mathrm{LBO}^{31}$ (а также эти же показатели с поправкой на отраслевые значения), независимыми переменными стали контрольные показатели, a также группа параметров, характеризующих склонность компании к предпринимательству: возможности и качество исследований, расходы на R\&D, уровень «коммерциализации», вложения в новые бизнесы. Общий результат можно охарактеризовать следующим образом: прибыльность компании после LBO положительно зависит от качества и возможностей $\mathrm{R} \& \mathrm{D}$, развития новых продуктов, уровня «коммерциализации», вложений в новые бизнесы, технологических возможностей. Что касается доли заемного капитала в структуре финансирования, зависимость неоднозначна: при сравнении результатов деятельности компаний до и после LBO прибыльность положительно зависит от уровня долга; при анализе результатов деятельности с учетом поправки на отраслевые значения зависимость отрицательна и незначима. Производительность компании положительно зависит от качества и возможностей $\mathrm{R} \& \mathrm{D}$, уровня «коммерциализации», развития новых продуктов; влияние уровня долга аналогично показателю прибыльности. Что касается незначимых контрольных переменных, возможное объяснение таково: возраст компаний не имеет значения из-за слишком короткого периода исследования; незначимость размера компании говорит о том, что улучшение результатов деятельности достигается не за счет краткосрочного уменьшения размера активов.

В целом гипотеза (H3) о взаимосвязи предпринимательской активности и результатов деятельности компаний подтверждается.

Итак, все гипотезы, выдвинутые автором статьи, были им подтверждены. Рассмотрим результаты исследования подробнее. Склонность компании к предпринимательской деятельности возрастает после LBO. Сравнение уровня корпоративного предпринимательства до и после LBO предполагает, что компании увеличивают возможности научных исследований и разработок как внутри организации, так и вне ее; они ищут возможности развития и внедрения новых продуктов и технологий; увеличивают инвестиции в рискованные активы. Эти результаты отражают снижение агентских издержек, изменение стимулов менеджеров из-за участия во владении бизнесом, рост свободы менеджеров в принятии стратегических решений. Стремление к предпринимательской деятельности отражает и влияние долгового финансирования после LBO, заставляющего менеджеров искать инновационные пути быстрой генерации денежных потоков для обслуживания долга.

\footnotetext{
31 Также проводилась серия тестов, где результаты деятельности после LBO выступали в роли независимой переменной. Но оказалось, что показатели предпринимательской активности лучше предсказывают прибыльность и производительность.
}

Выпуск \#2(6), 2008

(C) Электронный журнал Корпоративные Финансы, 2008 
Исследование показало, что число сотрудников, занятых в сфере R\&D, увеличивается, что расходится с некоторыми исследованиями других авторов [National Science Foundation, 1987]. Возможно, отобранные компании просто не снижали этих расходов. Значимых различий в соотношении расходов на $\mathrm{R} \& \mathrm{D}$ и объемом продаж компании до и после LBO выявлено не было. Это может означать, что рост корпоративного предпринимательства не зависит от увеличения расходов на $\mathrm{R} \& \mathrm{D}$.

Автор подтвердил, что результаты деятельности компании улучшились, показав, что изменения показателей прибыльности и производительности после LBO являются статистически значимыми. LBO-компании продемонстрировали более высокое изменение прибыльности и производительности по сравнению со средними значениями в соответствующих отраслях.

Изменение предпринимательской активности компаний после LBO сопровождается изменениями результатов их деятельности. Однако это не означает существования причинно-следственной связи, исследование лишь показало наличие положительной корреляции между ростом склонности к предпринимательству и одновременным изменением финансовых показателей.

Однако к интерпретации полученных результатов следует относиться с осторожностью, поскольку проанализированы далеко не все, а лишь некоторые показатели деятельности бизнеса. Также интересно было бы оценить влияние LBO на деятельность компании в течение более длительного периода, рассмотреть компании с другими характеристиками.

\section{5. Стимулы менеджмента и мониторинг до и после LBO}

Авторы [Thompson, Wright, 1991] выделяют две особенности сделок LBO: во-первых, участие менеджеров во владении бизнесом, которое влияет на их интересы и стимулы; и, вовторых, рост уровня долга ограничивает свободу менеджеров вследствие необходимости обслуживать долг. Указанные особенности предполагают создание корпоративной структуры с более низкими агентскими издержками по сравнению с ситуацией до LBO.

Данная статья обращается к вопросам исследования стимулов и мониторинга, возникающим в компании после LBO. Авторы анализируют средства контроля, появляющиеся на стадии выкупа акций компаний, на примере выборки британских компаний после выкупа компании менеджментом (MBO). MBO в британских компаниях отличаются от аналогичных сделок в США (подробнее отличия описаны ниже), однако исследование, безусловно, полезно для изучения особенностей сделок LBO во всех странах.

В Великобритании сделки МВО стали достигли пика популярности в 1980-х годах. Во второй половине десятилетия источниками сделок были в основном разделения диверсифицированных компаний (продажа части бизнеса), включая государственные предприятия, готовящиеся к приватизации. Среди отличий типичных британских MBO от американских сделок можно выделить следующие:

1. Средний размер сделки значительно ниже, чем в США.

2. Для британских сделок характерен более высокий уровень участия менеджмента в выкупе компании; обычно более 50\% капитала приобретается менеджерами (по выборке из 181 сделки в 79\% случаев менеджеры получили более 50\% компании, в $90 \%$ случаев - более $25 \%$ ).

3. Отличается уровень и тип долгового финансирования.

4. Рядовые сотрудники компании в сделках участвуют достаточно редко.

5. Так же как и в США, сделки в Британии сконцентрированы в зрелых отраслях, хотя охват отраслей несколько шире. В отличие от США среди британских МВО делается меньший акцент на улучшение результатов деятельности, целью некоторых сделок является расширение бизнеса с ранее ограниченными возможностями роста.

6. Независимо от того, котировались ли на рынке акции компании, продающей часть 
бизнеса по схеме МВО, компания, возникающая в результате выкупа, принимает закрытую форму.

Таким образом, типичная сделка МВО в Великобритании подразумевает покупку подразделения существующего бизнеса новыми владельцами, в основном представленными менеджментом самой компании-цели, с последующим созданием частной организации с высоким уровнем заемного капитала.

Высокий уровень сделок МВО с покупкой части бизнеса можно объяснить реакцией на неудовлетворительную систему стимулирования и контроля во многих диверсифицированных корпорациях Британии. Хотя, согласно классической теории [Williamson, 1975], многофилиальные организации обладают определенными преимуществами: например, внутренним рынком капитала, позволяющим им организовать процесс инвестирования внутри корпорации, не обращаясь на рынок. Несмотря на широкое распространение диверсифицированных организаций, в Великобритании в 1980-е годы, похоже, им не удавалось в полной мере воспользоваться их преимуществами, описанными в теории; часто внутрикорпоративное распределение ресурсов не отражает преимуществ внутреннего рынка капитала. В частности, конкуренция за инвестиционные ресурсы между подразделениями перекрывается либо централизованным распределением, либо слишком сильной автономией подразделений и удержанием излишков средств операционными единицами. При таких обстоятельствах децентрализация собственности и контроля подразделений путем проведения МВО может выступать очевидным средством снижения агентских издержек.

Объединение собственности и контроля в руках менеджеров зависит от внешнего финансирования, поэтому разделение диверсифицированной компании путем МВО создает новую агентскую проблему; однако теперь институт, финансирующий сделку, выступает в роли принципала вместо корпоративного центра. Особенности конфликта интересов в данном случае помимо всего прочего зависят от сочетания собственного капитала, долга и других инструментов финансирования. Как и прочих инвесторов, кредитора интересуют среднее значение $(\bar{\pi})$ и дисперсия $\left(V A R_{\pi}\right)$ прибыли новой компании. В свою очередь, прибыль компании после MBО будет зависеть от усилий менеджеров (е). Таким образом, функция полезности кредитора рассчитывается по следующей формуле:

$$
U^{P}=U^{P}\left[\bar{\pi}(e, R), V_{\pi}(e, R)\right],
$$

где $\frac{\partial U^{P}}{\partial \pi}>0, \frac{\partial U^{P}}{\partial V A R_{\pi}}<0, \frac{\partial \pi}{\partial e}>0 ;$

$\mathrm{R}$ - переменная стратегического выбора, такая, что: $\frac{\partial V A R_{\pi}}{\partial R}>0, \frac{\partial \bar{\pi}}{\partial R}>0$.

В рамках агентской проблемы сделка МВО должна максимизировать функцию (1) при ограничениях: интересы агентов (менеджеров) в новой компании должны соблюдаться в степени, не меньшей, чем вне организации; а также должна присутствовать совместимость по стимулам. На практике распределение выгод зависит от результатов переговоров принципалов и агентов. Более того, в противоположность агентским теориям, британские MBO чаще инициируются менеджерами-агентами (около 65\% сделок, рассмотренных в данной статье).

Сделка МВО может рассматриваться как сочетание финансовых соглашений, стимулирующих платежей и средств контроля. Причем создание этих элементов должно происходить одновременно, а не последовательно. К примеру, уровень заемного финансирования влияет на стимулы менеджеров принимать рискованные решения, и наоборот. Для преодоления сложностей, возникающих вследствие конфликта интересов менеджеров и внешних инвесторов, в литературе и на практике разработан ряд мер по стимулированию и контролю. Рассмотрим возможности их применения в случае МВО.

Во-первых, необходимо увеличить заинтересованность менеджеров в долгосрочных результатах деятельности организации. Как уже было описано выше, это достигается за счет Выпуск \#2(6), 2008 
участия менеджеров в выкупе компании.

Во-вторых, обязательства по обслуживанию долга дисциплинируют менеджеров, заставляя их придерживаться финансовых планов, установленных при совершении сделки; неспособность сделать это подвергает риску инвестиции самих менеджеров. То есть долговое финансирование не только стимулирует усилия менеджеров, но и ограничивает свободу распоряжения денежным потоком, показывая кредиторам, что у менеджеров мало шансов инвестировать в высокорискованные проекты.

B-третьих, Дженсен [Jensen, 1986] отметил, что смешанное финансирование - с привлечением собственного и заемного капитала - может способствовать снижению уровня конфликта интересов собственников-принципалов и менеджеров-агентов.

В Великобритании в сделках МВО часто используются дополнительные методы стимулирования менеджеров, в то время как непосредственный мониторинг осуществляется самими финансирующими институтами. Одним из таких методов является использование инструментов, позволяющих влиять на доли менеджеров во владении бизнесом в зависимости от среднесрочных результатов деятельности компании (equity ratchets). Они позволяют изменить структуру капитала компании, обычно через 3-5 лет после MBO, таким образом, что доля обыкновенных акций в руках менеджеров определяется прибыльностью компании или другими финансовыми показателями. Существует множество схем, одни из которых предполагают поощрение за хорошие результаты, другие - наказание за плохие результаты, есть и различные комбинации этих вариантов. Также схемы отличаются потенциальным размером изменения доли участия менеджеров.

По сути, такой инструмент является прямым условным контрактом (простейшая схема может рассматриваться как европейский колл-опцион с нулевой ценой исполнения). Увязывая вознаграждение менеджеров с результатами деятельности компании, подобная схема стимулирует усилия менеджеров и тем самым снижает проблему их оппортунистического поведения. К тому же схема способствует снижению вероятности неблагоприятного отбора - проблемы, когда принципал не способен определить настоящие качества агента до заключения сделки: вознаграждение по результатам деятельности компании будет невыгодно плохим менеджерам. Наконец, поскольку эти инструменты влияют на долю голосующих акций в руках менеджеров, они также оказывают влияние на систему корпоративного контроля; низкие результаты деятельности автоматически увеличивают долю голосующих акций в руках финансовых институтов, позволяя им заменить менеджеров.

Однако, несмотря на изложенные выше преимущества подобной схемы, существуют и некоторые проблемы. Во-первых, хотя использование инструментов, позволяющих влиять на доли менеджеров во владении бизнесом в зависимости от среднесрочных результатов деятельности компании, стимулирует усилия, прикладываемые менеджерами, в то же время ничто не удерживает их от следования высоко-рискованной стратегии. Во-вторых, могут возникнуть трудноразрешимые противоречия по условиям контрактов. Далее, бонусная система, основывающаяся на прибыли, является стимулом для манипуляции цифрами в отчетности; также и здесь менеджеры могут исказить докладываемые результаты деятельности с выгодой для себя (например, откладывая не самые важные расходы на более поздние периоды).

Таким образом, возможные трудности предполагают, что использования только этих инструментов явно недостаточно для защиты интересов внешних инвесторов. Следовательно, применение подобных схем должно дополняться другими средствами мотивации и мониторинга.

Некоторые экономисты [Cable, 1985; Stiglitz, 1985] заметили, что финансовые институты, кредитные портфели которых достаточно несбалансированны, имеют больше стимулов осуществлять мониторинг, нежели диверсифицированные акционеры. В случае исследуемых сделок МВО ситуация аналогичная; поскольку в течение нескольких лет после проведения сделки ни акции, ни долговые инструменты не торгуются на открытом рынке, 
благосостояние новых владельцев компании сильно зависит от результатов ее деятельности, что является хорошим мотивом для осуществления строгого контроля за деятельностью управляющих компании. Институты, финансирующие сделку, могут потребовать представительства в совете директоров компании после выкупа или, к примеру, предоставления более детальной финансовой отчетности. Однако эти действия требуют определенных ресурсов: представителю в совете директоров необходимо выплачивать компенсацию, предоставление информации требует от менеджеров затрат усилий и времени; и это не совсем согласуется с аргументом снижения агентских издержек.

Итак, помимо роста уровня долга и участия менеджеров во владении компанией существует множество инструментов обеспечения мотивации и мониторинга в приобретенной компании. Конечно, принципалы могут попытаться ввести все возможные меры, однако осознание потенциальных преимуществ и недостатков применения тех или иных инструментов подразумевает более осознанный выбор. Авторы статьи предполагают, что выбор инструментов контроля в первую очередь зависит от особенностей участия института в выкупе компании. Применение инструментов, позволяющих влиять на доли менеджеров во владении бизнесом в зависимости от среднесрочных результатов деятельности компании, стимулирует их усилия, поэтому ожидается, что использование данной схемы положительно связано с участием финансовых институтов в собственном капитале компании и отрицательно - с участием в заемном капитале. Назначение постороннего человека (не являющегося менеджером компании) в совет директоров защищает интересы инвесторов в сфере как акционерного, так и заемного капитала. Однако авторы предполагают, что заинтересованность в данном способе контроля зависит от срока предоставления долгового финансирования.

В Великобритании ситуация с данными о компаниях после выкупа практически не отличается от других стран, т.е. информации в открытых источниках нет. Данные для проведения исследования были взяты из сведений, собранных Центром изучения МВО университета Ноттингема, а также из анкет, заполненных представителями компаний, прошедших через МВО в 1983-1985 годы.

Согласно полученным данным, в выборке компаний использовались все четыре инструмента мотивации и мониторинга: инструменты, позволяющие влиять на доли менеджеров во владении бизнесом в зависимости от среднесрочных результатов деятельности компании (данная схема применялась в $27 \%$ компаний анализируемой выборки), назначение председателя совета директоров (16\% компаний выборки), назначение члена совета директоров (42\% компаний) и требование предоставления ежемесячной отчетности (80\% компаний). Для проведения исследования авторы вводят набор переменных (в основном бинарных), характеризующих компанию и команду менеджеров. Рассмотрим их подробнее: SIZE - размер приобретаемой компании (количество сотрудников на момент $\mathrm{MBO}$ ); MNFCTG - действует ли компания в производственной отрасли; MANEQ - доля голосующих акций в руках менеджеров после МВО; СЕОЕХР - стаж работы руководителя компании в текущей должности; TEAMNOS - число менеджеров, участвующих в выкупе.

Уровень долга является важным элементом при выборе инструмента контроля. Структура финансирования характеризуется следующими переменными: DEBT - отношение заемного капитала к собственному в момент выкупа; характер вложений основного инвестора - обыкновенные акций (ORD), конвертируемые обыкновенные акции (CONORD), привилегированные акции (PREF), облигации (DEBENTURE), долгосрочный или среднесрочный банковский кредит (LBNKDBT и MBNKDBT), банковский овердрафт (BANKOVDT) или другие инструменты (OTHER). Переменная MULTINS показывает, сколько - один или больше - ведущих инвесторов участвовало в сделке. Также вводятся переменные, характеризующие ведущего инвестора: выступает в этой роли клиринговый банк (CLEARER), коммерческий банк или венчурный инвестор (MERBANK) или же смешанная группа институтов.

Величина агентских издержек характеризуется вероятностью применения 
инструментов мотивации и мониторинга менеджеров. Оцениваемая модель выглядит следующим образом:

(2)

$$
P r_{i}=f\left(X_{j}, Y_{k}, Z_{l}\right)
$$

для $\mathrm{i}=1, \ldots, 4$.

$\mathrm{Pr}_{\mathrm{i}}$ - вероятность использования определенного инструмента мониторинга и мотивации;

$\mathrm{X}_{\mathrm{j}}$ - характеристики компании;

$\mathrm{Y}_{\mathrm{k}}$ - характеристики команды менеджеров и

$Z_{1}$ - вектор переменных, характеризующих финансовые инструменты и инвесторов финансовые институты.

В целом авторы предположили наличие положительной связи между использованием контролирующих инструментов и теми факторами, которые сами по себе позитивно влияют на уровень агентских издержек. То есть ожидается, что такие показатели, как размер компании, число участвующих в выкупе менеджеров, увеличивают требования по внедрению мотивационных и мониторинговых средств; в то же время, например, опыт работы генерального директора снижает необходимость мониторинга.

Зависимость (2) была исследована для каждого отдельного инструмента, а также для возможных сочетаний инструментов. При анализе отдельных инструментов лишь одна переменная из группы, характеризующей команду менеджеров, оказалась значимой - доля голосующих акций в руках менеджеров, причем зависимость в данном случае отрицательная. Это подтверждает предположение о том, что использование инструментов контроля в определенной степени заменяет способ снижения агентских издержек путем увеличения участия менеджеров в выкупе компании.

Была выявлена нелинейная зависимость между использованием мониторинговых инструментов и размером компании. Это говорит о нежелании инвестора тратить ресурсы на внедрение инструментов в случае маленьких инвестиций; вместе с тем выкуп достаточно больших компаний подразумевает приложение значительных усилий со стороны инвестора.

Участие основного инвестора в собственном капитале компании положительно влияет на вероятность использования инструментов, позволяющих влиять на доли менеджеров во владении бизнесом в зависимости от среднесрочных результатов деятельности компании, и представительства в совете директоров. В то же время переменные, характеризующие вложения инвестора в привилегированные акции, а также заемный капитал в виде облигаций, долгосрочного или среднесрочного кредита не оказывают влияния на использование этого типа инструментов. Выявлена лишь отрицательная связь данного инструмента с привлечением банковского овердрафта, что означает незаинтересованность институтов, предоставляющих краткосрочные обеспеченные кредиты, в создании системы стимулов для менеджеров.

Переменные, представляющие финансовые институты - количество ключевых инвесторов и тип инвестора, - оказались незначимы.

Оценка вероятности требования предоставления ежемесячной финансовой отчетности показала отличные от остальных результаты. Данный инструмент не может рассматриваться как аналог участия менеджеров во владении компанией. Значимая связь выявлена между требованием отчетности и различными типами финансирования. Действительно, данный инструмент мониторинга использовался в $80 \%$ компаний и примерно в половине этих случаев - в сочетании с другим/другими инструментами.

Анализ вероятности использования группы инструментов мотивации и мониторинга в целом подтвердил оценку отдельных инструментов. То есть использование инструментов мотивации и контроля нелинейно зависит от размера компании, отрицательно - от доли участия менеджеров в собственном капитале и привлечения банковского овердрафта, положительно - от участия основного инвестора в акционерном капитале компании.

Подведем итоги. Типичные сделки $\mathrm{MBO}$ в Великобритании представляют собой приобретение подразделения корпорации менеджерами самого подразделения. Авторы 
объясняют успешность сделок МВО сокращением агентских издержек. Однако выкупленная компания сталкивается с другой агентской проблемой - взаимодействием менеджеров и инвесторов (институтов, финансирующих сделку). Практика показывает, что существует множество путей решения этой проблемы. Выбор метода решения агентской проблемы зависит от условий финансирования сделки МВО; в то же время характеристики компании (кроме размера) и команды менеджеров оказываются не столь важны в объяснении выбора способа мониторинга.

\section{6. Проверка эффективности сделок LBO}

Целью статьи Булла [Bull, 1989] является сравнение эффективности бизнеса до и после leveraged buyout (далее - LBO). Автор хочет проверить теорию о том, что финансовые показатели деятельности компании улучшаются после выкупа; а также желает убедиться, насколько это улучшение зависит от потенциальной экономии на налогах.

В данной статье автор проводит сравнение деятельности компаний в течение 2 лет до LBO и 2 лет после LBO, исключая год проведения выкупа (поскольку в этот период высока вероятность нетипичных для компании событий). Необходимыми условиями включения компаний в выборку, помимо наличия информации, являлись: участие менеджеров в выкупе акций; то, что компания не была продана в течение 2 лет после выкупа; не было серьезных реорганизаций/реструктуризаций компании в течение 2 лет до и 2 лет после выкупа. Итак, анализируемая выборка включает 25 компаний, прошедших через процедуру LBO в $1973-$ 1981 годах. Цена приобретения акций компаний составляет от 11 млн долларов США до более чем 500 млн долларов; средняя стоимость выкупа составила 125 млн долларов США.

Отрасли, представленные в выборке, достаточно зрелые, не высокотехнологичные. Для компаний, работающих в подобных отраслях, характерны невысокие перспективы роста и хороший потенциал генерирования денежных потоков, что, в свою очередь, говорит о потенциально высоких агентских издержках.

Исследование проводится по усредненным финансовым показателям всех компаний выборки. Автор проводит несколько тестов: сравнение показателей эффективности компаний выборки до и после LBO; сравнение деятельности компаний выборки со среднеотраслевыми показателями.

Целью анализа является оценка степени изменения результатов деятельности компании, однако нет общепринятого набора показателей, применяемых для этой цели. Эффективность деятельности публичных компаний можно оценить, используя информацию о полученных дивидендах и изменении рыночной стоимости компании; но такие данные недоступны после LBO (а в некоторых случаях и до выкупа). Поэтому автор для оценки деятельности компаний пользуется бухгалтерскими показателями.

Возможность и корректность использования бухгалтерских показателей аргументируется ссылками на работы других исследователей [Foster, 1986], показавших существование связи между бухгалтерскими показателями и рыночной оценкой бизнеса. К примеру, по утверждению Фостера, тщательный анализ бухгалтерской отчетности - это один из способов выявления внутренней, истинной стоимости компании.

Часто для оценки эффективности деятельности бизнеса применяются показатели типа ROI (return on investment - доходность инвестиций); нередко эти показатели используются для расчета бонусов менеджерам. Однако толковые менеджеры находят множество способов достижения целевых значений данных коэффициентов, пренебрегая при этом долгосрочными целями компании. Таким образом, анализ однотипного набора коэффициентов может не выявить реального положения дел в компании. Поэтому желательно помимо индикаторов доходности исследовать показатели производительности, качества, гибкости, положения на рынке и т.д. К сожалению, нет достаточно четко разработанного набора подобных показателей. Автор в своем исследовании использует ряд коэффициентов, рассчитанных по данным бухгалтерской отчетности; причем это не только 
коэффициенты доходности, но и показатели, в определенной мере отражающие эффективность бизнеса, прибыльность и положение компании на рынке:

1. Отношение дохода от продолжающихся операций к собственным средствам на начало периода (Income from Continuing Operations (Earnings)/Beginning Equity).

2. Earnings before Interest and Income Taxes (EBIT)/Beginning Assets.

3. Sales/Beginning Assets.

4. Оборот (Sales).

5. Операционный доход к объему продаж (Operating Income/Sales).

6. Денежный поток к объему продаж (Cash Flow/Sales).

7. Income Tax Expense/Sales.

После осуществления всех необходимых корректировок (делающих возможным сравнение показателей) автор рассчитал средние значения и медианы указанных выше коэффициентов по компаниям выборки за 2 года до выкупа (Т-) и тот же период после выкупа (T+) за соответствующие 4-летние периоды, а также среднеотраслевые значения.

Автор анализирует отчетность компаний выборки за соответствующие 4-летние периоды и делает следующие наблюдения. Естественно, в период $\mathrm{T}+$ происходит значительный рост процентных расходов. Наблюдается снижение дохода от продолжающихся операций, хотя и в меньшей степени, чем рост процентных расходов. Рост расходов на выплату процентов по долгу приводит к ощутимому снижению расходов на выплату налогов. Увеличивается объем денежных средств, доступных для расходов на обслуживание долга. В период после LBO снижается размер активов компаний, что, возможно, является следствием более эффективного управления активами, а не до выкупа. Снижение собственного капитала отражает особенность сделок LBO - рост уровня долга. Также наблюдается снижение капитальных затрат в период $\mathrm{T}+$. Причинами подобной динамики может быть, например, снижение будущих производственных возможностей в силу необходимости выделения большего объема средств на обслуживание долга в ближайшей перспективе; или же, к примеру, рост эффективности капиталовложений.

Что касается сравнения компаний выборки со среднеотраслевыми значениями ${ }^{32}$, то средние значения по шести исследуемым показателям улучшились, и только объемы продаж незначительно снизились по отношению к отрасли. Заслуживает внимания изменение волатильности таких коэффициентов, как Earnings/Beginning Equity и Cash Flow/Sales. После LBO значение первого коэффициента сильно вырастает (если до выкупа компании выборки примерно соответствовали отрасли, то в период $\mathrm{T}+$ значение коэффициента более чем в три раза превысило среднеотраслевое); но и стандартное отклонение увеличивается в 10 раз. Второй коэффициент также начинает значительно превышать среднеотраслевое значение в $\mathrm{T}+$, но дисперсия при этом снижается. Такие изменения могут быть следствием значительного изменения системы управления компаниями после выкупа.

Серия тестов на проверку значимости подтвердила значимость (для уровня доверия 0.999) изменений показателей эффективности деятельности, как при сравнении самих компаний до и после LBO, так и при сравнении с отраслевыми значениями. Это означает, что эффективность деятельности (performance) компаний после LBO значительно отличается от периода до LBO.

Также автор подтвердил значимость изменений не только целой группы показателей, но и той их части, которая никак не связана с налоговой экономией, а именно EBIT/Beginning Assets, Sales/Beginning Assets, Operating Profit/Sales. Значимые изменения данного ряда коэффициентов подтверждают гипотезу о том, что LBO приводит к росту эффективности и прибыльности бизнеса даже без учета экономии на налогах за счет процентных платежей.

Помимо прочего автор проверяет значимость изменения каждой отдельно взятой переменной.

\footnotetext{
32 Проводилось сравнение следующих параметров: отношение среднего значения /медианы по выборке за период Т- /Т+ к среднему /медиане по отрасли за периоды T- /T+.
} 
1. Earnings/Beginning Equity. Рост данного показателя в периоде Т+ является значимым как при сравнении компаний выборки, так и при сравнении с отраслевыми значениями. Причины этого кроются частично в изменении структуры капитала компаний - снижения доли собственного капитала.

2. EBIT/Beginning Assets. Рост этой переменной также значим в двух группах сравнений.

3. Sales/Beginning Assets. Увеличение коэффициента незначимо, если сравнивать с деятельностью компаний до LBO, однако улучшение по сравнению с отраслью оказалось значимо, даже несмотря на наблюдаемое снижение относительных объемов продаж компаний-LBO по сравнению с отраслевыми значениями.

4. Объем продаж для выборки в целом увеличивается после LBO, однако темпы роста ниже среднеотраслевых. Согласно проведенным тестам, изменение оборота по сравнению с отраслью незначимо, однако не стоит забывать, что часто после выкупа компании новые владельцы избавляются от неприбыльных активов, что оказывает влияние на уровень продаж.

5. Operating Income/Sales. По компаниям выборки данный коэффициент кажется практически неизменным до и после выкупа, однако сравнение с отраслевыми значениями показывает значительное улучшение.

6. Cash Flow/Sales. Рост коэффициента в периоде T+ значим и при сравнении компаний выборки, и при сравнении с отраслью. Значительное увеличение денежных потоков является одной из основных задач LBO-компании-в связи с необходимостью соответствовать строгим требованиям по обслуживанию долга, видимо, исследуемые компании с этой задачей успешно справились.

7. Income Tax Expense/Sales. Снижение доли налоговых платежей в обороте компании также значимо.

Итак, подведем итоги. Финансовое состояние компаний после выкупа по сравнению с периодом до LBO улучшилось. Причем данное улучшение стало результатом изменения системы управления бизнесом, а не просто удачным стечением обстоятельств; также положительный результат не объясняется исключительно выигрышем от снижения налоговых платежей.

Изменение системы управления бизнесом подтверждается наблюдениями. Улучшение показателей Earnings/Beginning Equity и Cash Flow/Sales говорит о том, что изменились цели менеджмента: от снижения волатильности прибыли в отчетности к максимизации денежного потока, генерируемого бизнесом. Увеличение средней доходности собственного капитала может объясняться, во-первых, изменением структуры капитала в пользу заемного финансирования и, во-вторых, опять же, изменением системы управления. Причиной значительного роста волатильности доходов после LBO может быть появление предпринимательской жилки: владельцы идут на риск - стараются использовать видимые возможности извлечения выгоды. Иногда такие действия приносят прибыль, а иногда — и убытки.

Безусловно, важным преимуществом компаний после LBO является экономия на налогах, однако оно не единственное. Согласно проведенному исследованию, даже при отсутствии налогового выигрыша LBO будут иметь место. Несомненно, ожидаемая налоговая экономия учитывается в стоимости выкупаемых при LBO акций. Но значимость изменения группы показателей EBIT/Beginning Assets, Sales/Beginning Assets и Operating Profit/Sales доказывает, что важными причинами проведения LBO являются также ожидаемые улучшения эффективности и прибыльности бизнеса, - это так называемые реальные выгоды, а не перераспределение налогового бремени.

Таким образом, свой вклад в улучшение финансового положения компаний в результате LBO внесли все возможные теории, указанные выше. Что касается «политических» издержек - их снижение связано с переходом компаний из открытой в закрытую форму. Увеличение уровня долга, с одной стороны, ставит руководству компании 
новые цели - снижение долга; а с другой стороны - высокие расходы на обслуживание долга сокращают свободный денежный поток. Все вместе способствует уменьшению агентских издержек.

Данное исследование, конечно, полезно в плане выявления возможных причин и подтверждения положительного влияния LBO на деятельность компании. Но для полного исследования желательно также проанализировать воздействие LBO в условиях рецессии, выявить зависимость выкупа акций от размера компании, исследовать больший период и расширить набор показателей эффективности деятельности.

\section{7. Заключение}

В данной статье были рассмотрены причины эффективности трансформации компаний открытого типа в компании закрытого типа на примере LBO. Основными теориями, объясняющими эффективность LBO, являются поведенческая теория (возникновение предпринимательского взгляда на компанию), теория агентских издержек, теория свободного денежного потока, теория снижения «политических» издержек и теория снижения налогового бремени. Основными являются теория агентских издержек и поведенческая.

Более подробно сравнивались поведенческая теория с теорией агентских издержек, а также было проведено тестирование каждой из них. Наконец, анализ эффективности LBO на основе комплекса показателей продемонстрировал, что каждая из перечисленных теорий имеет право на существование, объясняя изменения в одном или нескольких аспектах деятельности компании после LBO. Таким образом, все теории, объясняющие эффективность LBO, являются взаимодополняющими, а не взаимозаменяющими, и при анализе конкретных ситуаций в реальных компаниях должны рассматриваться в комплексе.

\section{Список литературы}

\section{Книги:}

1. Foster G. Financial Statement Analysis. 2nd Ed. Prentice Hall: Englewood Cliffs, N.J. 1986.

2. National Science Foundation. Instructions for Survey of Industrial Research and Development. Washington, DC: US Department of Commerce. 1987.

3. Williamson O.E. Markets and Hierarchies: Analysis and Antitrust Implications, New York: Free Press. 1975.

4. Williamson O.E. The economic institutions of capitalism. New York: Free Press. 1985.

\section{Статьи в журналах:}

1. Andrews W., Dowling M. Explaining performance changes in newly privatized firms // Journal of Management Studies, 35, 1998, p. 601-618.

2. Bull I. Financial Performance of Leveraged Buyouts: an Empirical Analysis // Journal of Business Venturing, 4, 1989, p. 263-279.

3. Cable, J. Capital market information and industrial performance: the role of West German banks // Economic Journal, 95, 1985, p. 118-132.

4. Demsetz, H. Towards a theory of property rights // American Economic Review, 57, 1967, p. $347-359$.

5. Francis J., Smith A. Agency costs and innovation: Some empirical evidence // Journal of Accounting and Economics, 19, 1995, p. 383- 409.

6. Holmstrom B. Agency costs and innovation // Journal of Economic Behavior and Organization, 12,1989 , p. 305-327.

7. Jensen M. Agency costs of free cash flow, corporate finance and takeovers // American Economic Review, May, 1986, p. 326-329.

8. Jensen M. The Takeover Controversy: Analysis and Evidence // Midland Corporate Finance 
Journal, 4(2), 1986, p. 6-32.

9. Jensen M. Eclipse of the public corporation // Harvard Business Review, 67(5), 1989, p. $61-74$.

10. Jensen M., Meckling W.H. Theory of the Firm: Managerial Behavior, Agency Costs and Ownership Structure // Journal of Financial Economics, 3, 1976, p. 305-360.

11. Kaplan S. The effects of management buyouts on operating performance and value // Journal of Financial Economics, 24, 1989, p. 217-254.

12. Lowenstein L. Management buyouts // Columbia Law Review, 85, 1985, p. 730_784.

13. Robbie K., Wright M. Managerial and ownership succession and corporate restructuring: The case of management buy-ins // Journal of Management Studies, 32, 1995, p. 527-550.

14. Stiglitz J.E. Credit markets and the control of capital // Journal of Money, Credit and Banking, 17, 1985, p. 133-152.

15. Thompson R.S., Wright M. UK Management Buy-Outs: Debt, Equity and Agency Cost Implications // Managerial and Decision Economics, Vol. 12, No. 1, 1991, p. 15-26.

16. Uhlenbruck N., De Castro. Privatization from the acquirer's perspective: A mergers and acquisitions based framework // Journal of Management Studies, 35, 1998, p. 619-640.

17. Wright Mike, Hoskisson Robert E., Busenitz Lowell W., Dial J. Entrepreneurial Growth through Privatization: the Upside of Management Buyouts // Academy of Management Review, Vol. 25, No 3, 2000, p. 591-601.

18. Zahra S. A. Corporate Entrepreneurship and Financial Performance: the Case of Management Leveraged Buyouts // Journal of Business Venturing, 10, 1995, p. 225-247. 